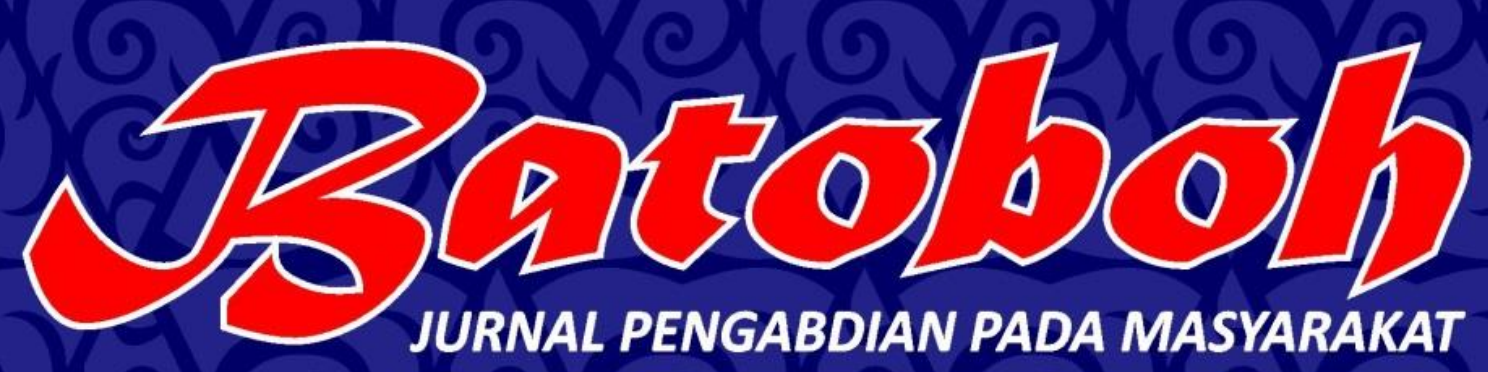

ISSN: 2548-5458

Volume 1

Nomor 2

JURNAL PENGABDIAN PADA MASYARAKAT

Oktober 2016

hlm. 131-266

Yusfil, Zulkifli, Erlinda

PENERAPAN TEKNOLOGI SENI PADA SANGGAR SENI TRADISIONAL

DI KABUPATEN PESISIR SELATAN SUMATERA BARAT

Asril

PELATIHAN LAGU SIONTONG TABANG, KURETA MANDAKI, DAN OYAK TABUIK

PADA GRUP GANDANG TASA ANAK-ANAK, SANGGAR ANAK NAGARI DESA SUNGAI PASAK, KOTA PARIAMAN

Nofrial, Wahyono, Riski Rahmat Kurniawan Dan Alek Hengki Ziora

PEMANFAATAN SERBUK GERGAJI MENJADI PRODUK KERAJINAN DI WAN PERABOT,

TARANTANG KECAMATAN HARAU, 50 KOTA

Dira Herawati, Muhammad Husni, A Nick Koto Agam, Eza Ramadhani

PELATIHAN FOTOGRAFI PADA KEGIATAN EKSTRA KURIKULER DI SMKN 2 PADANGPANJANG

F. X Yatno Karyadi, Eriswan, Bari, Rahmat, Irham

PELATIHAN PEMBUATAN VIDEO DAN FOTO MAKRO MENGGUNAKAN TABLE-TOP STUDIO UNTUK SISWA SMA

Novina Yetri Fatrina, Ediantes, Putri Andam Dewi, Suri Handai Yani

PELATIHAN TEKNIK MEMBUAT RIAS EFEK UNTUK FILM FIKSI PADA SMK 2 PADANGPANJANG

Rosta Minawati, Heri Sasongko, Gilang Febriano, Vini Rusmana

PENGENALAN PRODUKSI FILM DOKUMENTER BAGI SISWA/ SISWI SEKOLAH MENEGAH ATAS

Hafif HR, Fahmi Marh, Ade Sulistiawan, Dino Ashari

PENERAPAN MULTI DISIPLIN SENI DALAM KEGIATAN DRUMBAND PADA EKSTRAKURIKULER SMA 3 PADANGPANJANG

Febri Yulika, Selvi kasman, Putri Khairina Masta

PENINGKATAN KOMPETENSI GURU MELALUI PELATIHAN PENULISAN KARYA TULIS ILMIAH

Darmansyah, Novesar Jamarun, Firdaus, Indra Arifin, Fitra Muhaddis

PELATIHAN INSTRUMEN MUSIK TRADISIONAL MINANGKABAU DI MAN 2 GUNUNG PADANGPANJANG 



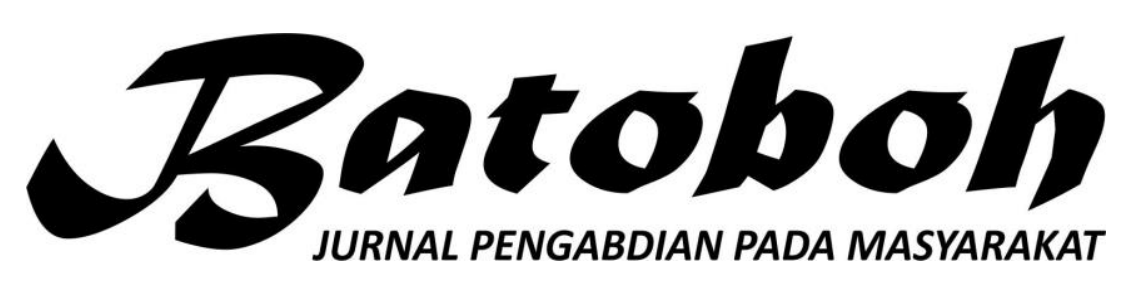

ISSN: 2548-5458 Volume 1, Nomor 2, Oktober 2016, hlm. 131-266

Terbit dua kali setahun pada bulan April dan Oktober. Pengelola Jumal Pengabdian pada Masyarakat merupakan subsistem LPPMPP Institut Seni Indonesia (ISI) Padangpanjang.

\author{
Pengarah \\ Rektor ISIPadangpanjang \\ Penanggung Jawab \\ Kepala Pusat Penerbitan ISI Padangpanjang \\ KetuaPenyunting \\ Andar Indra Sastra \\ Penyunting \\ Asril \\ Sahrul \\ RostaMinawati \\ Harissman \\ Pimpinan Redaksi \\ Saaduddin \\ Redaktur \\ Liza Asriana \\ Rori Dolayance \\ Tata Letak dan Desain Sampul \\ Yoni Sudiani \\ WebJurnal \\ Thegar Risky
}

Alamat Pengelola Jumal Batoboh:LPPMPP ISI Padangpanjang

Jalan Bahder Johan Padangpanjang 27128, Sumatera Barat; Telepon (0752) 82077 Fax. 82803;

e-mail; batoboh@gmail.com

Catatan. Isi/Materi jurnal adalah tanggung jawab Penulis.

Diterbitkan Oleh

Institut Seni Indonesia (ISI) Padangpanjang 


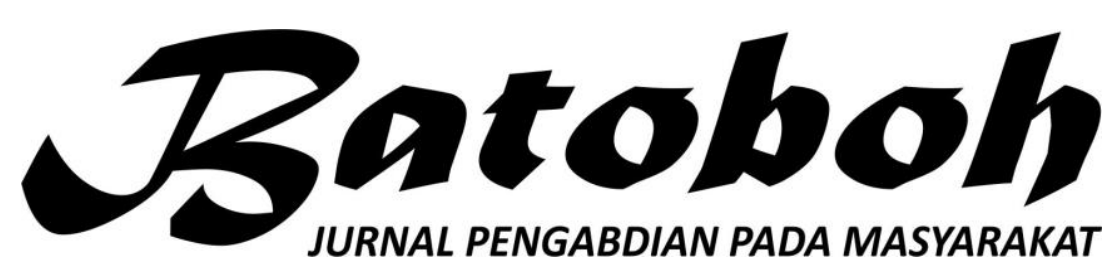

ISSN: 2548-5458 Volume 1, Nomor 2, Oktober 2016, hlm. 131-266

\section{DAFTAR ISI}

\begin{tabular}{|l|l|}
\hline \multicolumn{1}{|c|}{ PENULIS } & \multicolumn{1}{c}{ JUDUL } \\
\hline Yusfil, Zulkifli, Erlinda & $\begin{array}{l}\text { Penerapan Teknologi Seni Pada Sanggar Seni } \\
\text { Tradisional Di Kabupaten Pesisir Selatan Sumatera } \\
\text { Barat }\end{array}$ \\
Asril & $\begin{array}{l}\text { Pelatihan Lagu Siontong Tabang, Kureta Mandaki, } \\
\text { Dan Oyak Tabuik Pada Grup Gandang Tasa Anak- } \\
\text { Anak, Sanggar Anak Nagari Desa Sungai Pasak, } \\
\text { Kota Pariaman }\end{array}$ \\
$\begin{array}{l}\text { Nofrial, Wahyono, Riski } \\
\text { Rahmat Kurniawan Dan } \\
\text { Alek Hengki Ziora }\end{array}$ & $\begin{array}{l}\text { Pemanfaatan Serbuk Gergaji Menjadi Produk } \\
\text { Kerajinan Di Wan Perabot, Tarantang Kecamatan } \\
\text { Harau, 50 Kota }\end{array}$ \\
\hline
\end{tabular}

HALAMAN

Dira Herawati,

Muhammad Husni, A

Nick Koto Agam, Eza

Ramadhani

F. X Yatno Karyadi,

Pelatihan Fotografi Pada Kegiatan Ekstra

Kurikuler Di SMKN 2 Padangpanjang

131-144

$145-164$

Eriswan, Bari, Rahmat, Irham

Novina Yetri Fatrina, Ediantes, Putri Andam Dewi, Suri Handai Yani

Pelatihan Pembuatan Video Dan Foto Makro

190-200 Menggunakan Table-Top Studio Untuk Siswa SMA

Pelatihan Teknik Membuat Rias Efek Untuk Film 201-212 Fiksi Pada SMK 2 Padangpanjang

Rosta Minawati, Heri Sasongko, Gilang

Pengenalan Produksi Film Dokumenter Bagi $213-227$ Febriano, Vini Rusmana

Hafif HR, Fahmi Marh, Ade Sulistiawan, Dino Ashari Siswa/Siswi Sekolah Menegah Atas

$165-181$ 182-189

Febri Yulika, Selvi Kasman, Putri Khairina Masta

Darmansyah, Novesar Jamarun, Firdaus' Indra Arifin, Fitra Muhaddis

Penerapan Multi Disiplin Seni Dalam Kegiatan Drumband Pada Ekstrakurikuler SMA 3 Padangpanjang

Peningkatan Kompetensi Guru Melalui Pelatihan Penulisan Karya Tulis Ilmiah

Pelatihan Instrumen Musik Tradisional $256-266$ Minangkabau Di MAN 2 Gunung Padangpanjang

\footnotetext{
Peraturan Direktur Jenderal Pendidikan Tinggi Kementerian Pendidikan Kebudayaan Republik Indonesia Nomor 1 Tahun 2014 Tanggal Tentang Pedoman Akreditasi Terbitan Berkala Ilmiah. Jumal Batoboh Terbitan Vol. 1, April dan Oktober 2016 Memakaikan Pedoman Akreditasi Berkala Ilmiah Tersebut.
} 



\title{
PENERAPAN MULTI DISIPLIN SENI DALAM KEGIATAN DRUMBAND PADA EKSTRAKURIKULER SMA 3 PADANGPANJANG
}

\author{
Hafif HR, Fahmi Marh, Ade Sulistiawan, Dino Ashari \\ Prodi Seni Karawitan \\ Fakultas Seni Pertunjukan- ISI Padangpanjang. \\ Jl. Bahder Johan, Padangpanjang, Sumatra Barat \\ hafif_hr@yahoo.com
}

\begin{abstract}
ABSTRAK
Kegiatan Drumband merupakan suatu rangkaian kegiatan yang cukup komplek, tidak hanya berfokus kepada unsur musikal namun lebih luas dari pada itu, seni Drumband perwujudannya membutuhkan disiplin seni lainnya seperti seni tari, desain komunikasi visual dan seni kepemimpinan serta seni baris berbaris. Hal tersebut terangkum dalam Seni Drumband dengan penjabaran yang terdapat pada keutuhan drumband seperti pada section Battery, section Hornline dan section color guard.
\end{abstract}

Kata Kunci :Drumband, Seni Musik, Seni Tari dan seni Desain Visual. 


\section{PENDAHULUAN}

Drumband danMarchingband di Indonesia terus berkembang dinaungi oleh organisasi Persatuan Drum Band Seluruh Indonesia (PDBI) yang merupakan organisasi yang pertama menaungi kegiatan ini secara formal.seiring dengan perkembangannya kegiatan ini menjadi kegiatan yang lebih berfokus pada penampilan musikal dan visual yang mengadaptasi metode permainan musik yang berasal dari group drum band dari Amerika, sehingga hasil dari penampilan dari kegiatan ini lebih bercorak dan lebih menarik.Kegiatan Marchingband atau Drumband merupakan kegiatan bermain secara team. Dimulai dari kelompok kecil (section) sampai pada kelompok yang besar (corps), mereka dituntut untuk melakukan latihan atau praktik guna membangun keutuhan team serta melakukan aktivitas komunikasi secara verbal dan visual. Baik secara internal antar anggota, maupun unsur luar (eksternal) dengan tujuan meningkatkan kemampuan hubungan kemanusiaan atau human skill. Selain itu dalam kegiatan drumband dan marchingband setiap kali latihan selalu dilaksanakan kegiatan harian apel, piket dan lain-lain, dalam pengorganisasian kegiatan drumband dan marchingband menggunakan sistem komando yang digunakan dalam militer seperti komandan, kepala staf dan lain-lain, hal ini bertujuan untuk membina mental militer atau military style dan memupuk nilai juang siswa.

Drumband dan marchingband merupakan bentuk kegiatan yang sering dijadikan sebagai kegiatan pembinaan dan pengembangan diridi sekolah yang dilaksanakan pada pogram ekstrakurikuler, kegiatan ini digunakan sebagai pembukaan maupun penutupan pada acara ceremonial dan hari besar nasional lainnya, sebagai seni yang komplek penggarapannya membutuhkan teamwork dan mesti dihadapi dengan serius dan membutuhkan pendanaan yang cukup banyak dalam menjalankannya, sehingga ia mesti dihayati dengan sepenuh hati dan perasaan plus logika, tak ketinggalan pula stamina tubuh mesti prima. Menurut Marko $\mathrm{S}$ Hermawan dalam tulisannya "Trendmarching dan Drumband" (2002), wilayah ini cukup sulit ketimbang belajar ilmu-ilmu eksakta 
yang hanya mengandalkan logika semata.

Untuk wilayah propinsi Sumatra

Barat kegiatan Drumband dan Marchingband yang dilakukan di sekolah belum begitu maksimal, banyak sekolah memiliki drumband atau marchingband namum minim terhadap pembinaan secara kontinitas dan lebih bersifat incidental, seperti pawai perayaan hari besar negara,upacara kenegaraan, pawai khatam al-quran, hasil survey yang telah dilakukan khususnya untuk wilayah Padangpanjang ada beberapa factor yang menyebabkan hal tersebut terjadi diantaranya :

- Sekolah tidak memiliki pembiayaan karna untuk melaksanakan ivent kegiatan ini membutuhkan pembiayaan yang cukup banyak, pembiayaan latihan seperti biaya pelatih, kostum, konsumsi, taransportasi, akomodasi dan lainnya,

- Pengetahuan yang kurang dalam melakukan pembinaan dan pelatihan seperti kurangnya pengetahuan secara musikologi,pengatahuandrill atau baris berbaris, minimnya penguasaan teknik dan metode pembelajaran colorguard dan lainnya.

- Pelatih yang kebanyakan di datangkan dari luar sekolah seperti para pelatih yang didatangkan dari alumni marchingband Karang Putih PT Semen Padang dan beberapa alumni Institut Seni Indonesia Padangpanjang yang membutuhkan pembiayaan yang cukup besar, ada pembiayaan perpaket dan ada pembiayaan secara regular.

- Instrument yang kurang memadai seperti banyaknya home industry yang ada sekarang memicu terhadap hasil produksi instrument, dengan keterbatasan anggaran dan pengetahuan sering pihak sekolah dalam melakukan pengadaan barang yang kurang berkualitas sehingga berdampak pada hasil yang akan diwujudkan.

- Minimya apresiasi atau dukungan dari pihak sekolah dan orang tua karna kebanyakan pemahaman mereka terhadap kegiatan ini dianggap tidak memiliki output yang jelas, hal tesebut tidak dapat kita salahkan secara sepihak kerena memang kebanyakan sekolah dalam pelaksanaan pembinaan dan 
pelatihan kegiatan marchingband belum memiliki target pencapaian yang mengarah pada pembentukan karakter siswa dan metode pelatihan yang kurang menarik dan lain sebagainya.

Institut Seni Indonesia

Padangpanjang sebagai lembaga tinggi seni memiliki tanggungjawab secara moril dan memiliki peran penting dalam melihat fenomena ini, masih kurangnya peran dan tanggungjawab lembaga ini dikarnakan dalam pelaksanaan pelatihan dan pembinaan kegiatan drumband dan marchingband tidak hanya pada aspek musikal saja namun banyak hal yang mesti disinergikan, namun dari banyaknya aspek yang dibutuhkan pada kegiatan tersebut pada prinsipnya Institut Seni Indonesia Padangpanjang memiliki kualifikasi tehadap hal tersebut. di wilayahPropinsi Sumatra Barat kegiatan pembinaan dan pelatihan didominasi oleh para alumni marcher karang putih PT.Semen Padang sebagai komunitas yang memiliki kompetensi di bidang tersebut, hal ini tidak bisa dipungkuri karna mereka memiliki kemampuan,penguasaan, pengalaman terhadap kegiatan tersebut, sebagai lembaga Institusi Pendidikan Seni yang ada di Padangpanjang sudah saatnya untuk berorientasi membekali diri dalam penguasaan seni drumband dan marchingband, karna dari kompleksitas seni yang ada pada kegiatan ini pada prinsipnya lembaga pendidikan tinggi seni seperti Institut Seni Indonesia Padangpanjang memiliki kualifikasi dibidang seni tersebut. SMAN 3 Padangpanjang dalam menunjang kegiatan ekstrakurikuler drumband mencoba melakukan kerjasama dengan lembaga Institut Seni Indonesia padangpanjang dalam hal pengabdian masyarakat yang merupakan salah satu point dari tri dharma Perguruan tinggi, sebagai lembaga pendidikan tinggi seni bertanggungjawab secara moril terhadap pembinaan pengembangan seni yang ada di masyarakat. Sehingga kegiatan ini mesti dilakukan pembinaan dan pengembangannya.baik pelatih battery (Perkusi), drill (baris-berbaris), hornline (instrument Melodi tiup), lyra dan colorguard (bendera). Penguasaan terhadap hal tersebut belum mencapai hasil yang maksimal, karna masih kurangnya pengetahuan dan pengalaman terhadap kegiatan tersebut, 
padahal peluang terbuka bagi lembaga ini untuk melakukan pembelajaran dan mengaplikasikan ilmu seni yang dipelajari.

\section{PEMBAHASAN}

\section{A. Disiplin ilmu}

Seni yang dibutuhkan PadaKegiatan Drumband dan MarchingbandBerbagai disiplin ilmu turut menentukan suksesnya pertunjukan drumband dan marchingband, disiplin tersebut tidak hanya dilihat dari kostum yang mereka gunakan tetapi meliputi lagu, koreografi, langkah, visual dan musik. Adapun uraianpenerapan multi disiplinseni yang dilakukan dalam kegiatan drumband dan marchingband antara lain :

\section{Seni Musik}

a. Arransemen dan orkestrasi merupakan hal utama dalam seni drumband dan marching band, ketika kita mengarranser ulang lagu yang sudahada maka secara otomatis pekerjaan orkestarasi sebagai pelengkap dan penyempurnaan dari apa yang akan kita lakukan dalam mengarranser lagu. Proses penampilan drumband dan marchingbandterdapat ruang kreatifitas dalam membuat arransemen dan orkestrasi terhadap instrument yang ada. Jenis ritmik lagu yang dimainkan oleh orkestrasi drumband dan marchingband lambat laun kian rampak dan beragam, balutan dan hentakan musik pop, dangdut, blues bahkan rock sekalipun mampu dipersembahkan dengan apiknya, aransemen dan orchestrasi yang memadai menjadi kata kunci di samping keuletan dan ketekunan dalam berlatih. Membuat arransemen maupun orkestrasi pada saat ini dapat dilakukan dengan menggunakan teknologi, Adanya software untuk penulisan notasi musik seperti Encore, Sibelius dan yang lainnya sangatlah membantu dalam membuat sebuah arransemen dan orkestrasi. Melodi,chord serta perpaduan bunyi semua instrument atau orkestrasi yang akan dibuat dapat didengarkan langsung dan juga dapat diperdengarkan kepada para marcher dalam proses latihan 
baik sectional maupun gabungan. Sehingga dapat membantu proses pemahaman terhadap bentuk dan bagian lagu yang dimainkan serta membantu dalam mengontrol intonasi nada oleh para marcher atau pemain drumband dan marchingband, namun apabila ketergantungan terhadap tekhnologi yang ada menjadi hal utama maka fantasi dalam pembauatan arransemen dan orkestrasi bagi seorang arranger menjadi berkurang, padahal dalam pembuatan arransemen dan orkestrasi mesti berdasarkan kaidah-kaidah ilmu musik yang ada agar karya yang dibuat sistematis dan terstruktur, Irwan (2007; h 3 )

b. Seksional Battery atau instrument perkusi non melodi dapat dilakukan secara parallel antara motif ritme melodi dengan motif ritme perkusi, dan juga dapat dibuat secara independen yakni antara motif ritme perkusi berbeda sama sekali dengan motif ritme melodi, pada keutuhan arransemen seksional Battery diberi ruang khusus untuk melakukan demonstrasi dengan motif ritmik yang energik dan teknik seperti Gripping atau cara menggenggam stik, Fulcrum Drumming atau titik poros pada stik,Rudiment (Roll Rudiments, Diddle Rudiments, Flam Rudiment, Drug Rudiments) dan masih banyak pembagian dari teknik rudiment.Disamping teknik permainan stik Postur tubuh seorang pemain Battery menjadi hal yang penting untuk diperhatikan guna keseragaman dalam membentuk style dan karakter Showmanship sebuah kelompok battery, Sehat Kurniawan saiman (2012;h 1-7).

c. Bagian instrument Brass pada marchingband dan drumband terbuka ruang untuk membuat keutuhan lagu menjadi berkualitas bila memiliki kemampuan untuk menterjemahkan bagian yang akan dibuat serta penggunaan harmoni yang lebih komplit dan tepat guna pada instrument. Disamping arransemen pada 
sectional brass sangat dibutuhkan teknik tiupan yang benar guna menghasilkan bunyi secara maksimal sehingga perlu penguasaan terhadap beberapa teknik tiupan seperti teknik pernafasan diafragma, the lips (bibir) yang bergetar tanpa menggunakan mouthpiece atau mangkok tiup untuk memproduksi suara, koordinasi antara otot dan bibir harus terjalin dengan baik pada saat mempraktekkannya, the muscle (otot) dari bibir dan wajah yang harus dilatih secara baik dan rilek sehingga menghasilkan suara yang akurat pada interval yang berbeda-beda, the tounge (lidah) yang memproduksi artikulasi yang berbeda-beda, pada permaianan instrumen tiup brass pada format marchingband dan permainan instrumen pianika pada format drumband menjadi penting untuk diperhatikan tekhnik the left hand (tangan kiri) menahan instrument dengan kuat dan stabil, the fingers of the right hand (jari-jari tangan kanan) masing-masing jari harus dilatih secara terus menerus dan pengaturan penjarian dalam memainkan melodi pada instrumen pianika., the air (udara) yang dihasilkan dari diafragma secara maksimal guna memproduksi hasil bunyi yang baik. the wind power (kekuatan angin) belajar mengontrol suara keras dan lembut dan menghasilkan mutu suara yang baik untuk nada rendah maupun nada tinggi, Sehat Kurniawan (2013: h. 1-2)

\section{Seni Tari}

Pelaksanaan seni drumband dan marchingband tidak hanya berfokus pada aspek musikal, namun masih banyak aspek lainnya yang mesti dikuasai secara utuh, salah satunya aspek seni tari atau gerak, penguasaan gerak tari muncul ketika para pemain berperan sebagai color guard, dalam pembelajaran color guard ada beberapa aspek yang harus diketahui, diawali dengan pengertian tentang color guard, color artinya warna secara tersirat color merupakan suatu istilah bendera kenegaraan (nation color) 
sedangkan guard artinya penjaga, pengawal atau pasukan pengawal,color guard berarti pasukan atau penjaga bendera kenegaraan disertai pataka dan benner sebagai identitas. Selain itu mesti dipahami juga arti dan tujuan kehadirannya color guard dalam seni marchingband diantaranya memberikan keindahan dan daya tarik seluruh pagelaran, menunjukkan komunikasi terhadap pagelaran (Sopuan 2012: h 12).Dalam mempraktekkan seni color guard banyak hal yang harus dilatih untuk dikuasai, penguasaan peralatan yang digunakan (equipment) seperti Flag (bendera),Rifle (senjata mainan) dan Sabre (pedang mainan) serta melatih teknik dasar dari setiap alat yang akan digunakan.setelah mempelajari teknik dalam memainkan peralatan (equipment) dilanjutkan dengan membentuk pola-pola gerak atau koreografi yang disesuaikan dengan musik yang telah dipelajari.

\section{Seni Desain Visual}

Rancangan pola display yang akan digunakan dikonsep secara seni desain agar proses latihan pada display dapat berjalan secara efektif, seiring perkembangan teknologi pembuatan desain display dapat digunakan dengan menggunakan sofwar yang telah ada bahkan dapat dirinci secara frase atau chard dari gerakan satu, dua, tiga dan seterusnya dan disesuaikan dengan musik yang dibuat. Hal ini sangat membantu secara konseptual, diharapkan pola atau desain yang telah dibuat pada sofwar tersebut mestinya dilakukan metode visual guna memberikan pemahaman terhadap konsep display yang akan diterapkan oleh para marcher. Dalam proses pembuatan display dilakukan secara dua tahapan,tahapan pertama pengenalan display yang disesuaikan dengan lagu yang ada tanpa menggunakan instrumen yang biasa disebut dengan tahapan latihan display kering, dan dilanjutkan dengan tahapan latihan display dengan menggunakan instrumen atau latihan display basah, dimana para marcher memiankan display yang telah dilatih sambil memainkan instrumen. Tahapan pelatihan display ini memakan waktu yang cukup lama dalam proses kegiatan 
drumband maupun marchingband dan dilakukan di ruang yang lebih luas. Hasil display yang telah dibuat dapat dimaksimalkan dengan didukung oleh properti dan kostum yang digunakan oleh para marcher.

1. Seni Kepemimpinan dan baris Berbaris (dril).

Pimpinan dalam kegiatan drumband dan marchingband biasa disebut dengan fillcommander,seorang fillcommander diberikan pembekalan tentang kepemimpinan, pemahaman terhadap keutuhan konsep yang telah dibuat, penguasaan display yang ada, penguasaan terhadap lagu yang telah dilatih serta kemampuan memberikan aba-aba atau code dengan pasti dan tegas sesuai dengan ketentuan atau kaidah yang terdapat pada keutuhan konsep baik secara musical maupun visual. Selain itu anggota marcher juga dibekali dengan pengatuan tentang drill atau aturan langkah dan baris berbaris, aturan baris berbaris yang ada pada seni drumband dan marchingband berbeda dengan baris berbaris yang ada pada militer dan pramuka dan paskibraka. Pada seni drumband dan marcingband baris berbaris yang dilakukan ada beberapa pola diantaranya :

a. Pola atau postur tubuh dalam melaksanakan baris bersbaris, sikap sempurna pada pelaksanaan drill baik di tempat maupun berjalan memiliki ketentuan, sebagai seorang marcher terlihat gagah dan tegap maka postur tubuh menjadi hal yang utama untuk diperhatikan seperti sikap tubuh yang tegap dengan posisi punggung tegak lurus dan pandangan lurus ke depan.

b. Pola gerak kaki ditempat atau jalan ditempat, pada seni drumband dan marchingband pola gerak kaki yang diangkat hanya bagian tumit belakang dengan ujung-ujung jari kaki masih berada dilantai berbeda halnya dengan baris berbarisnya meliter, kaki harus diangkat dari lantai secara bergantian, Pola hadap kiri dan kanan serta balik kiri dan kanan juga berbeda pada seni drumband dan marchingband, pada seni baris berbarisnya militer pola yang dibaut selalu dihitung dengan tiga hitungan, namun pada seni drumband dan marchingband 
pola hitungannya hanya dua baik hadap maupun balik kiri dan kanan, pola gerak kaki pada pelakasanaan hadap maupun balik kiri dan kanan berporos pada tumit.

c. Pola gerak kaki berjalan (marching manufer) dilakukan dengan pola rolling, dimana langkah kaki diawali dengan tumit menyentuh lantai secara bergulir diakhiri dengan ujung jari kaki seperti menginjitkan kaki dan dilakukan secara bergantian baik melangkah ke depan, kebelakang maupun kesamping .pada pelaksanaan berjalan apabila mau berbelok ke kiri atau ke kanan posisi tubuh tetap tegap menghadap ke depan.

\section{B. Tahapan Pembelajaran}

Proses perwujudan sebuah karya seni drumband dan marchingband tidak dapat diwujudkan secara bersamaan dari setiap section namun harus melalui tahapan-tahapan, hal ini yang diterapkan pada kegiatan pengabdian masyarakat yang dilaksanakan di SMAN 3 Padangpanjangantaralain:

1. Tahapan Sektional, langkah awal dari proses latihan yang dilakukan dimulai latihan secara terpisah sesuai dengan section masingmasing, seperti section Colorguard, section hornline, Section Battery. Tahapan sectional diawali dengan memberikan sosialisasi terhadap peran dan fungsi dari section yang ada dan memberikan apresiasi dengan menggunakan metode audio visual, yakni memberikan apresiasi lewat dokumentasi terhadap section yang ada pada kegiatan drumband dan marchingband yang lain sebagai bahan apresiasi dan komparasi, tujuannya dilakukan guna memberikan stimulant atau rangsangan minat awal kepada para marcher, menurut Nurul Zuriah dalam Yatim Riyanto (1996 :47) Menyatakan bahwa tindakan yang merupakan ujicoba ide ke dalam praktek untuk memperbaiki atau mengubah sesuatu agar memperoleh dampak nyata dari situasi. Sehingga metode ini menjadi hal yang mesti dipertimbangkan untuk dilakukan. Langkah berikutnya pada tahapan section ini menggunakan Metode Sampling atau memberikan contoh serta penerapan teknik dari masing sectional(colorguard,hornlinedan 
Battery) agar para marcher mendapatkan pemahaman terhadap capaian apa yang akan dilakukan nantiknya, seorang instruktur tidak hanya berbicara depan para anak didiknya namun mestinya memberikan contoh terhadap apa yang akan dilakukan atau dipraktekkan biasa disebut dengan penerapan langsung yang bersifat Partisipatori ,Nurul Zuriah (2005 : 73)

2. Tahapan penggabungan sectional, langkah berikut yang dilakukan setelah tahapan sectional selesai dilakukan, menggunakan metode pemutaran audio dari konsep keutuhan karya agar seluruh Marcher memahami capaian yang akan mereka lakukan. Setelah audio diperdengarkan langkah berikutnya memberikan pemahaman analisis bentuk terhadap keutuhan karya. Seorang musisi maupun pengkarya yang baik tidak hanya membutuhkan imajinasi, akan tetapi pengetahuan akan ilmu musik seperti pemahaman ilmu harmoni, ilmu bentuk dan lainnya sehingga mempermudah untuk melakukan atau mempraktekkannya, Irwan (2007; h.69), sehingga pemahaman terhadap bentuk dan bagian lagu penting untuk dipahami oleh para marcher dengan tujuan untuk mempermudah menghafal dan memahami lagu yang dimainkan. Pada tahapan ini para marcher memainkan instrumen digabung secara keseluruhan section dan dilakukan secara berulang-ulang sampai keutuhan dan gabungan dari section terdengar dengan baik.

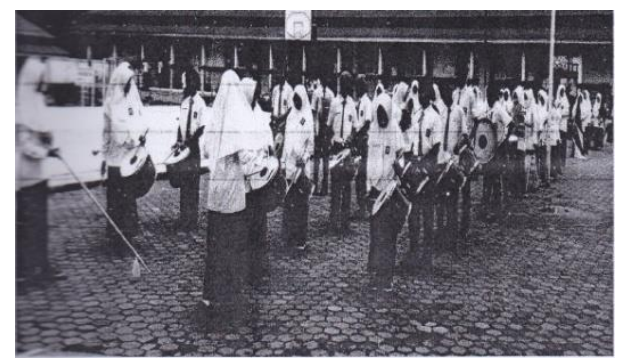

Gambar 1.

Latihan Gabungan semua unsur Drumband (Foto; Hafif, 2016)

3. Tahapan pembelajaran dasar-dasar drill (baris-berbaris), diawali melalui apresiasi dalam bentuk pemutaran dokumentasi audio visual, Setelah apresiasi dilakukan para instruktur mendemonstrasikan dasar-dasar drill dan mendemonstrasikan pola-pola gerak yang dilakukan sesuai desain display yang telah dikonsep, gaya drill atau baris berbaris yang ada pada kegiatan drumband dan marchingband berbeda dengan kegiatan baris berbaris 
militer,pramuka dan paskibraka sebagaimana yang telah duraikan sebelumnya, perbedaan tersebut terdapat pada gerak di tempat atau jalan di tempat,hadap kiri, hadap kanan dan balik kanan, gerak berjalan (manufer Marching) dengan posisi punggung tegap lurus dan badan mengarah ke depan, aba-aba yang digunakan juga berbeda. Setelah dipahami dilanjutkan dengan pelaksanaan drill oleh para marcher secara bergantian sesuai dengan frase atau char yang telah dibuat..

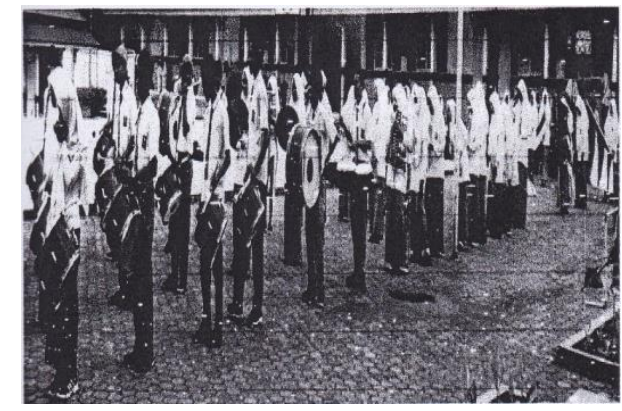

Gambar 2.

Latihan dasar-dasar Drill (baris-berbaris) (Foto: hafif, 2016)

4. Tahapan

Latihan

konfigurasi/display Kering (tanpa Instrumen), setelah melakukan tahapan-tahapan diatas selanjutnya para marcher diberikan pemahaman atau sosialisasi terhadap pola konfigurasi yang akan dibuat, seiring dengan perkembangan teknologi sofwar pembuatan konsep display memberikan kemudahan bagi para instruktur untuk merangkai desain yang ingin dicapai, sebelum memulainya perlu kiranya melakukan metode pemutaran audio visual guna memberikan gambaran capaian yang akan dilakukan nantinya, dalam penjabaran konsep konfigurasi yang akan dibuat perlu membagi gerak sesuai frase atau chard yang disesuaikan dengan lagu.tahapan ini dilakukan tanpa menggunakan instrument dengan membuat program tryout disesuaikan dengan gambaran luasnya lapangan yang bakan digunakan dalam lomba nantinya.

5. Tahapan Latihan konfigurasi/display Basah (menggunakan Instrumen), masingmasing pemain dilatih memainkan lagu dan gerak sesuai chard atau frase yang telah dirancang. sambil memainkan lagu yang telah dibuat dengan menggunakan instrumen, hal ini dilakukan dengan cara yang sama pada tahapan latihan kering dengan membuat program tryout di lapangan baik indoor maupun outdoor sesuai kondisi lapangan 
yang akan digunakan pada lomba atau tempat penampilan, agar marcher mudah beradaptasi.

\section{Peluang Lembaga Seni dalam Pembinaan dan Pelatihan Drumband dan Marchingband .}

Proses penggarapan seni drumband dan marchingband melibatkan berbagai unsur seperti instruktur, keorganisasian, sekolah atau yayasan, pihak pemerintah dan pihak terkait lainnya. Institut Seni Indonesia sebagai sebuah lembaga pendidikan seni memiliki tanggung jawab secara moril terhadap perkembangan dan keberlanjutan kegiatan ini, karna kegiatan ini merupakan bentuk kegiatan yang dikategorikan kebudayaan tinggi yang digarap secara serius dan terhindar dari budaya yang serba instan, kegiatan inipun dapat dijadikan sebagai media untuk pembinaan dan pengembangan diri para marcher yang sebagian besar terdiri dari para siswa sebagai generasi muda bangsa yang terlatih dan berkarakter, Seni pada umunya dan seni musik pada khususnya dapat menyentuh kehidupan manusia secara menyeluruh ia adalah suatu disiplin ilmu yang melibatkan sisi emosional intelektual dan fisikal. Melalui kegiatan kesenian seseorang bukan saja dapat mengembangkan kreatifitasnya tapi juga kepercayaan diri,sikap pengertian, kemampuan bekerja sama,kesadaran spiritual dan memiliki apresiasi yang memadai (Yusup Oeblet :2008, h 1). Secara kualifikasi Institut Seni Indonesia Padangpanjang mampu untuk bergerak di bidang seni drumband dan marchingband karna lembaga ini memiliki program studi Musik, Tari dan Desain Komunikasi Visual,namun hal ini masih belum dilakukan, karna minimnya pengalaman di bidang tersebut serta kompleksitas tuntutan dalam melakukan kegiatan tersebut baik tuntutan pemahaman terhadap seninya maupun tuntutan diluar seni itu sendiri.

\section{KESIMPULAN}

Melalui tulisan ini diharapkan adanya penyadaran dari pihak lembaga pendidikan tinggi yang bergerak di bidang seni agar memberikan respon bahwa ada peluang dalam berkreatifitas dan mengaplikasikan keilmuan seni yang dipelajari secara kolaboratif terhadap kegiatan seni drumband dan 
marchingband, kenyataan yang ada masih minimnya campur tangan pihak institusi seni terhadap pembinaan dan pengembangan kegiatan tersebut karna begitu kompleknya seni yang ada dalam penggarapan sebuah karya seni drumband danmarchingband. Langkah awal yang sudah dilakukan oleh jurusan musik dengan memasukkan dalam kurikulum matakuliah drumband dan marchingand namun belum berjalan secara maksimal, karna kurangnya fasilitas pendukung dalam mengaplikasikannya dan pemberdayaan sumber daya manusia yang belum maksimal, mungkin dengan cara melakukan magang sumber daya yang ada ke komunitas atau kelompok drumband dan marchingband yang sudah profesioanal atau workshop terhadap kegiatan yang bersangkutan dengan mendatangkan tenaga professional di bidangnya dan hal lainnya, sehingga memberikan celah atau ruang untuk memahami pentingnya menangkap peluang ini untuk dijadikan proses berkreatifitas dalam penerapan keilmuan seni yang dipelajari dan tidak tertutup kemungkinan menjadi ruang profesi.

\section{KEPUSTAKAAN}

Hikmat Budiman, 2001, "Lubang Hitam Kebudayaan", Kanisius, Jogjakarta.

Irwan, 2007, "Buku Ajar Arransemen I", Sekolah Tinggi Seni Indonesia, Padangpanjang.

Marko S. Hermawan, 2002, "Trendmarching dan Drumband": Situs Library Indonesia Marching Band Indonesia, Jakarta.

Nurul Zuriah, 2005, Metodologi Penelitian Sosial dan Pendidikan" Bumi Aksara, Jakarta

Sehat Kurniawan Saiman, 2012, "Brass Clinik" , Diktat Workshop Marching Band,PasamanBarat.

Sopuan, 2012, "Color Guard Clinik", Diktat Workshop Marching Band, Pasaman Barat.

Titi Nur Vidyarini, 2008, "Budaya Populer dalam Kemasan Program Televisi", Jurnal Ilmiah Scriptura, Jakarta.

Yusup oeblet, 2008, “ Menuju Pendidikan Musik Yang Terbarukan", Depok 
FILOSOFI "BATOBOH": Dalam masyarakat Minangkabau upacara-upacara yang dilakukan sebelum mendirikan bangunan baik Rumah Gadang maupun Balairung (Balai Adat) serta bangunan lainnya yang dikenal dengan beberapa upacara yang disebut dengan batoboh. Batoboh berasal dari kata Taboh yang artinya menebang atau mengambil sesuatu, jadi dengan mengambil kayu dihutan sebagai bahan utama dalam membangun rumah dan bangunan lainnya. Upacara Batoboh ini sangat bermanfaat bagi masyarakat Minangkabau yaitu dapat meningkatkan Gotong-Royong dan solidaritas antar sesama suku Minangkabau karena memberi kesempatan kepada kerabat-kerabat untuk terlibat dalam pembangunan rumah serta bangunan lain.

Alamat Redaksi: LPPMPP ISI Padangpanjang Jalan Bahder Johan Padangpanjang 27128 Sumatera Barat Telp. (0752) 485466, Fax.(0752) 82803 e-mail: batoboh@gmail.com

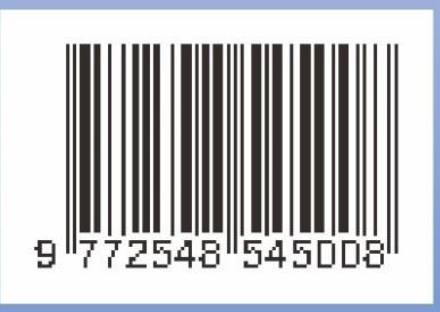

